\title{
Energy Intake, Meal FreQuency, and HeALth: A Neurobiological Perspective*
}

\author{
Mark P. Mattson \\ Laboratory of Neurosciences, National Institute on Aging Intramural Research Program, \\ Baltimore, Maryland 21224, and Department of Neuroscience, Johns Hopkins University \\ School of Medicine, Baltimore, Maryland 21205; email: mattsonm@grc.nia.nih.gov
}

Key Words BDNF, caloric restriction, insulin resistance, obesity, serotonin

Abstract The size and frequency of meals are fundamental aspects of nutrition that can have profound effects on the health and longevity of laboratory animals. In humans, excessive energy intake is associated with increased incidence of cardiovascular disease, diabetes, and certain cancers and is a major cause of disability and death in industrialized countries. On the other hand, the influence of meal frequency on human health and longevity is unclear. Both caloric (energy) restriction (CR) and reduced meal frequency/intermittent fasting can suppress the development of various diseases and can increase life span in rodents by mechanisms involving reduced oxidative damage and increased stress resistance. Many of the beneficial effects of CR and fasting appear to be mediated by the nervous system. For example, intermittent fasting results in increased production of brain-derived neurotrophic factor (BDNF), which increases the resistance of neurons in the brain to dysfunction and degeneration in animal models of neurodegenerative disorders; BDNF signaling may also mediate beneficial effects of intermittent fasting on glucose regulation and cardiovascular function. A better understanding of the neurobiological mechanisms by which meal size and frequency affect human health may lead to novel approaches for disease prevention and treatment.

\section{CONTENTS}

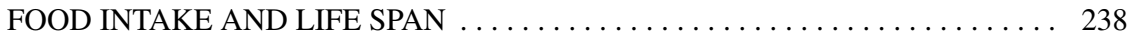

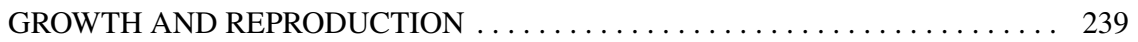

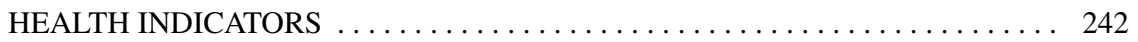

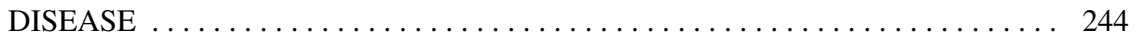

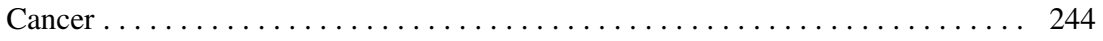

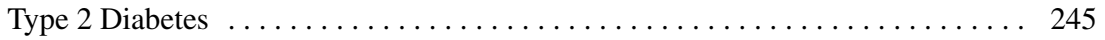

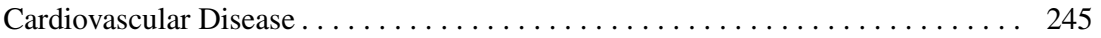

Neurodegenerative and Psychiatric Disorders . . . . . . . . . . . . . 246

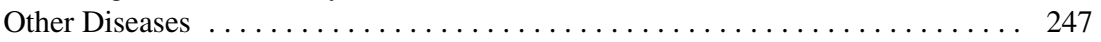

${ }^{*}$ The US Government has the right to retain a nonexclusive, royalty-free license in and to any copyright covering this paper. 
CELLULAR AND MOLECULAR MECHANISMS $\ldots \ldots \ldots \ldots \ldots \ldots \ldots \ldots \ldots$

THE BRAIN MEDIATES HEALTH EFFECTS OF DIETARY

FRUGALITY AND EXCESSES . . . . . . . . . . . . . . . . . . . . . . . 249

BRAIN-DERIVED NEUROTROPHIC FACTOR . . . . . . . . . . . . . . 250

Serotonin . . . . . . . . . . . . . . . . . . . . . . . . . . . . . . 250

IMPLICATIONS FOR IMPROVING HEALTH $\ldots \ldots \ldots \ldots \ldots \ldots \ldots \ldots \ldots .252$

\section{FOOD INTAKE AND LIFE SPAN}

More than 70 years ago, it was discovered that reducing energy intake during adult life can increase the life span of laboratory rodents (87). The ability of caloric restriction (CR) during adult life to lengthen life span has been observed consistently in many different species of mammals (134). In all such energyrestriction studies described in this chapter the control group was fed ad libitum and the CR diet group received amounts of micronutrients equivalent to those consumed by the control group. It should therefore be kept in mind that, with regard to food intake, ad libitum feeding in the laboratory is not the norm for rodents in the wild. Instead, the control animals are overfed and overweight. Both the amount of the energy restriction and the duration of restriction period influence the extent to which life span is increased (134). Reductions in energy intake of $30 \%-40 \%$ below the ad libitum level increase both the average and maximum life span of mice and rats by $30 \%-40 \%$. Maximum extension of life span is achieved when $\mathrm{CR}$ is initiated in young adult animals, with diminishing extension as the time of onset of energy restriction is delayed. The amount by which CR extends life span in rodents also depends upon the baseline energy intake of the control group and the magnitude of CR; life span is progressively increased with progressive reductions in energy intake from the ad libitum amount up to approximately $50 \%$ reduction, beyond which further CR results in increased mortality. A study of the effects of CR (30\% reduction in calories) on the life span of rhesus monkeys was initiated in 1987. The data obtained to date suggest that the health of the monkeys on CR is improved and their life span is increased compared with the monkeys on the control diet (82). In humans, overeating promotes diseases in multiple organ systems that usually shorten life. In the United States, overeating is now considered a leading cause of morbidity and mortality $(13,16)$. Particularly disturbing is the rapid increase in overweight children with insulin resistance who are at very high risk for diabetes and vascular diseases that shorten life (94).

By comparison with the intense interest in the quantity (and quality) of food intake on health and longevity, the influence of meal frequency has been understudied. Intermittent fasting regimens, such as every-other-day fasting (EODF, the most commonly employed protocol in animal studies), can increase the life span of rats and mice $(19,45,47)$. Both mean and maximum life spans are increased by EODF in different species and in most (but not all) strains of rodents (134). The relationship of the age of initiation of intermittent fasting and life span was studied in Wistar rats. Increases in life span were obtained by EODF during all or part of 
the life span, but there was not a strong correlation between the effects of EODF on growth and body composition and its effect on life span (10). Life span extension by EODF is associated with improved glucose metabolism and cardiovascular function, and increased function and resilience of the brain $(4,84,130)$.

In contrast to animal studies, the results of human studies that have attempted to determine the effects of CR and meal frequency on health have been difficult to interpret because of their design. The studies of starvation by Ancel Keys were perhaps the first to suggest that severe long-term CR may actually have health benefits in humans (67). More recently, participants in the Biosphere study who were forced to eat a low-calorie diet over a period of approximately two years exhibited highly significant decreases in blood pressure and insulin and cholesterol levels (129). Health benefits of smaller, more frequent meals are suggested from survey-based evaluations of the association between meal frequency and obesity, hypercholesterolemia, and glucose intolerance (35), and from the assessment of the effects of short-term (days to weeks) high and low meal-frequency diets on glucose regulation $(65,66)$. It has been suggested that skipping breakfast is unhealthy (66), but other findings indicate that skipping breakfast can decrease risk factors for cardiovascular disease and diabetes (80). Data from an epidemiological study of 6928 adults revealed no association between breakfast skipping and mortality (138). Studies of different populations of humans that periodically fast as part of their religion suggest health benefits of such reduced meal-frequency diets (2). Unfortunately, most of the studies on meal frequency and human health that have been performed were conducted over short time periods (days to weeks) with low numbers of subjects and did not control for calorie intake, exercise, and other important variables. However, in a recent study of nonobese human subjects maintained for 22 days on an EODF regimen, it was shown that this intermittentfasting diet results in a highly significant decrease in insulin levels (57).

In principle, there should be a window of energy intake that promotes optimum health, and this should also be true for meal frequency (Figure 1). However, the actual values for optimum calorie intake and meal frequency may vary considerably among individuals because of factors such as their activity level, age, and sex. For example, a physician or dietician can be confident in recommending that a 30-yearold overweight sedentary female who consumes 3000 calories per day reduce her intake to 2000 calories per day. However, it is unclear to what extent (if any) a 30-year-old normal-weight active, but hypercholesterolemic, male who consumes 2300 calories per day would benefit from reducing his intake to 2000 calories per day. In regard to meal frequency, there are insufficient data from human studies to justify any recommendations.

\section{GROWTH AND REPRODUCTION}

As might be expected, CR and intermittent fasting can reduce body weight in adults, an effect that is often desirable. CR reduces body weight and retards body weight gain in adults of all species of organisms (134). The growth-retarding effect 


\begin{tabular}{|c|c|}
\hline \multirow{5}{*}{$\begin{array}{l}\text { Obesity and } \\
\text { disease zone }\end{array}$} & Excessive Energy Intake/Meal Frequency \\
\hline & CARDIOVASCULAR DISEASE STROKE \\
\hline & DIABETES $\quad$ CANCER \\
\hline & NEURODEGENERATIVE DISORDERS \\
\hline & KIDNEY AND LIVER DISEASE \\
\hline & $\begin{array}{l}\text { PREMATURE DEATH } \\
\text { PRA }\end{array}$ \\
\hline $\begin{array}{l}\text { Disease } \\
\text { risk zone }\end{array}$ & $\begin{array}{l}\text { High Energy Intake/Meal Frequency } \\
\text { INSULIN RESISTANCE } \\
\text { HYPERTENSION } \\
\text { OXIDATIVE STRESS }\end{array}$ \\
\hline $\begin{array}{l}\text { Optimum } \\
\text { health zone }\end{array}$ & $\begin{array}{l}\text { Low Energy Intake/Meal Frequency } \\
\text { INSULIN SENSITIVITY } \\
\text { LOW BLOOD PRESSURE } \\
\text { LOW BODY TEMPERATURE }\end{array}$ \\
\hline $\begin{array}{l}\text { Anorexia and } \\
\text { starvation zone }\end{array}$ & $\begin{array}{l}\text { Excessively Low Energy Intake } \\
\text { TISSUE DAMAGE/ORGAN FAILURE }\end{array}$ \\
\hline
\end{tabular}

Figure 1 Influence of different levels of energy intake and meal frequency on health. Excessive energy intake results in obesity and a strong likelihood of morbidity and premature death. High levels of energy intake and meal frequency may increase the risk of diabetes, cardiovascular diseases, cancer, and neurodegenerative disorders. Moderate reductions in energy intake and meal frequency promote optimum health, whereas excessive dietary restriction, as in anorexia nervosa, can result in morbidity and mortality.

of CR was partially prevented by leptin administration in mice; this was associated with reduced insulin-like growth factor (IGF)-1 levels but increased levels of IGF-1 receptor (41). These findings suggest important roles for leptin and IGF-1 signaling mechanisms in the effects of CR on growth. Studies performed approximately 40 years ago demonstrated that intermittent fasting periods of days to weeks could be effective in the correction and control of obesity in humans $(34,121)$. In rodents, the effects of EODF on body weight differ among species and strains. For example, Wistar and Sprague-Dawley rats exhibit 20\%-30\% reductions in body weight (46, 130), whereas C57BL/6 and A/J mice show little reduction in body weight during periods of many months on $\operatorname{EODF}(4,47)$. Interestingly, while the growth of young adult rats is retarded by EODF, regular exercise (treadmill running) enhanced the growth of the EODF rats (115). In a study of the eating patterns of children in the Bogalusa Heart Study, there was a marked increase in the percentage of children who skipped breakfast (from 8\% to 30\%) from 1973 to 1978, but there was no association between this change in meal pattern and overweight status (102).

The development of embryos, infants, and juveniles is very sensitive to energy intake. Accordingly, and in contrast to adults, it is critical that developing humans receive sufficient energy to permit normal growth and physical and cognitive development. Physiological adaptations can occur that modify the effects of CR 
on body weight and development. When pregnant Sprague-Dawley rats are maintained on CR $(15 \%, 30 \%$, or $50 \%$ restriction) during gestation, they continue to gain weight, in contrast to nonpregnant rats, which lose weight on the $30 \%$ and $50 \%$ CR diets (109). Moreover, the growth of the developing embryos was not reduced in the rats on the $\mathrm{CR}$ diets. These findings suggest that pregnant rats are able to modify their metabolism during pregnancy in ways that allow normal growth of their embryos. However, people who are undernourished during fetal and early postnatal development are at increased risk for developing type 2 diabetes as adults (51). An association between low birth weight and the risk of type 2 diabetes in adult life has been established in several different human studies. Maternal CR and maternal diabetes may alter the development of the endocrine pancreas in the developing fetus in ways that predispose the offspring to insulin resistance later in life (108). Male rats growth-retarded during fetal life and cross-fostered shortly after birth to normal lactating dams reach a normal weight by weaning but have a reduced longevity. Thus, energy restriction during embryonic and early postnatal life can promote disease in adult life and may reduce longevity. CR can have adverse effects on reproduction in women. For example, in one study of 47 women who were underweight because they practiced CR, 29 had unexplained infertility and 18 had menstrual dysfunction (8). When 36 of these women subsequently followed a dietary regimen to increase their weight, 19 of 26 infertile women conceived spontaneously, and 9 of 10 women with secondary amenorrhea resumed menstruation. Thus, the practice of CR in young women may be a cause of unexplained infertility and menstrual disorders. Studies of women with anorexia nervosa with or without amenorrhea, and similar in body mass index, showed that the eumenorrheic women had higher levels of body fat, leptin, and IGF-1 compared with the amenorrheic women (95). The latter findings suggest that interindividual differences in neuroendocrine responses to severe CR may determine whether women suffer reproductive abnormalities.

Animal studies have documented effects of CR on specific aspects of reproductive physiology in females and males. Rat pups whose mothers had been fed either ad libitum or $50 \% \mathrm{CR}$ were maintained on ad libitum or CR diets. CR during embryonic development and during postnatal development significantly impaired reproduction and decreased milk yield (90). When young adult Kunmin mice were maintained on a $35 \% \mathrm{CR}$ diet for three months, their maturation of reproductive function was delayed and their fertility was decreased (140). Sperm motility was reduced and numbers of abnormal sperm increased in mice on the CR diet. When young adult male Wistar rats were maintained on CR, there was a significant decrease in the size of their testis and epididymis, levels of circulating testosterone were reduced, and their copulatory efficiency was reduced (116). Although severe CR has adverse effects on fertility and reproduction, more moderate levels of CR can prolong the reproductive period in rodents (91). In a National Institute on Aging study of monkeys maintained on $30 \%$ CR for more than 15 years, the reproductive system of females did not appear to be adversely affected $(82,113)$. Collectively, the available data suggest that moderate levels of CR may not adversely affect growth and reproduction, whereas more severe energy restriction is 
detrimental. The effects of intermittent fasting on reproductive systems remain to be determined.

\section{HEALTH INDICATORS}

A large amount of information on the physiological effects of energy restriction and, to a lesser extent, reduced-meal-frequency diets has been collected from studies of rodents, monkeys, and humans $(56,82,134)$. Examples of several reproducible changes documented in rodents and primates are presented in Table 1.

TABLE 1 Physiological changes associated with energy restriction and intermittent fasting in mammals

\begin{tabular}{|c|c|c|}
\hline Variable & Energy restriction & Intermittent fasting \\
\hline Blood & $\left(56^{*}, 82^{*}, 134^{*}\right)^{\mathrm{r}, \mathrm{m}, \mathrm{h}}$ & $\left(1,3,32,37,57,83^{*}\right)^{r, h}$ \\
\hline Glucose & Decrease & Decrease \\
\hline Insulin & Decrease & Decrease \\
\hline IGF-1 & Decrease & No change or increase \\
\hline Triglycerides & Decrease & na \\
\hline LDL cholesterol & Decrease or no change & Decrease or no change \\
\hline HDL cholesterol & Increase & Increase or no change \\
\hline Ketones & No change & Increase \\
\hline Cardiovascular & $\left(39,56^{*}, 82^{*}, 134^{*}, 142\right)^{r, m, h}$ & $(112,130)^{r, h}$ \\
\hline Blood pressure & Decrease & Decrease \\
\hline Heart rate & Decrease & Decrease \\
\hline Atherosclerosis & Decrease & na \\
\hline Muscle & $\left(56^{*}, 133,134^{*}\right)^{r, h}$ & $(37)^{r}$ \\
\hline Insulin sensitivity & Increase & Increase \\
\hline Lipid accumulation & Decrease & Decrease \\
\hline Brain & $(15,27,62,81,92)^{\mathrm{r}, \mathrm{m}}$ & $\left(71,72,75,83^{*}\right)^{r}$ \\
\hline Cognition & Enhanced memory & Enhanced memory \\
\hline Motor function & Improved & Improved \\
\hline Neurogenesis & No change & Increase \\
\hline Pain threshold & Increased & na \\
\hline BDNF, GDNF & No change or increase & Increase \\
\hline
\end{tabular}

FOOTNOTES: r, rodents; m, monkeys; h, humans.

ABBREVIATIONS: BDNF, brain-derived neurotrophic factor; GDNF, glial cell line-derived neurotrophic factor; HDL, high-density lipoprotein; IGF, insulin-like growth factor; LDL, low-density lipoprotein; na, not assessed.

* References 56, 82, 83, and 134 are review articles that include references to the relevant primary studies. 
A sustained reduction in body temperature occurs in mammals on CR diets, whereas in animals on EODF, body temperature is decreased during the fasting period and increases in the fed state (130). Rats and mice maintained on $40 \% \mathrm{CR}$ or EODF exhibit reductions in circulating levels of insulin and glucose (4). Another highly reproducible effect of both CR and EODF is to decrease resting heart rate and blood pressure and to improve cardiovascular stress adaptation $(39,130$, 142). Insulin resistance and hypertension are major risk factors for coronary and cerebrovascular artery disease, consistent with vasculoprotective effects of CR and intermittent fasting. Changes in blood lipids that occur in rodents, monkeys, and humans on CR [decreased low-density lipoprotein (LDL) cholesterol and triglycerides and increased levels of high-density lipoprotein (HDL) cholesterol] would also be expected to suppress atherosclerosis $(39,82)$. Consistent with a cardioprotective effect of regular fasting in humans, Moslems who fast during the month of Ramadan have reduced levels of LDL cholesterol and increased levels of HDL cholesterol (112).

$\mathrm{CR}$ and intermittent fasting have beneficial effects on immune function in adults. Data suggest that both reduced-energy and reduced-meal-frequency diets can reduce inflammatory responses, as indicated by reduced production of tumor necrosis factor by macrophages (127). T lymphocyte responses to concanavalin A and responses of B lymphocytes to pokeweed mitogen were reduced in obese subjects compared with normal weight controls, and these impairments in immune responsiveness were reversed by $\mathrm{CR}$ (123). On the other hand, the production of inflammatory cytokines and other mediators of inflammation are decreased in rodents on CR. In addition, allergic reactions to commonly encountered allergens, such as dust mite antigen, are decreased in rodents on CR (29). Overall, the effects of $\mathrm{CR}$ on the immune system appear to be beneficial, promoting the eradication of infectious agents while limiting tissue damage caused by inflammation. However, cell-mediated immune function is impaired in anorexia nervosa (79), which suggests that extreme CR has detrimental effects on the immune system. The effectiveness of the immune system in battling infection is also affected by meal frequency. When weanling mice were subjected to EODF, the responses of their leukocytes to immune challenge were reduced during the first month on the diet and recovered to normal levels by six months (78). In contrast, the immune responses of 17-month-old mice were improved by EODF. Collectively, the available data suggest that CR and intermittent fasting enhance immune function in adults but may compromise certain immune responses in infants and juveniles.

$\mathrm{CR}$ and intermittent fasting can influence indicators of health of the nervous system. CR (40\%) in female mice during their adult life prevented age-related declines in learning and motor coordination (62). Analysis of the structure of dendrites in layer $\mathrm{V}$ pyramidal neurons in the parietal cortex of rats that had been maintained on either EODF or ad libitum diets revealed that EODF suppresses age-related loss of dendritic spines, a structural indicator of synapses (97). Such effects on the structure of neurons may underlie the beneficial effects of dietary restriction in preserving learning and memory and motor function in rodents. 
Age-related alterations in neurotransmitter-synthesizing enzymes and neurotransmitter receptors in the brain were suppressed in rats that had been maintained on an EODF diet during their adult life compared with rats fed ad libitum (75). EODF was particularly effective in increasing cholinergic markers (choline acetyltransferase and muscarinic receptors). Another reported physiological effect of EODF on the nervous system is increased pain thresholds in mice (27); however, its implications for health are not clear. The influence of overeating on the health of the central and peripheral nervous systems are poorly understood, but it does appear to have numerous adverse effects that can lead to morbidity and mortality (84).

Energy restriction and reduced meal frequency can increase the resistance of organisms to various types of stress. For example, intermittent fasting increased the resistance of rats to cold stress and resulted in changes in collagen and bone consistent with an antiaging effect (60). Thermoregulation is compromised during aging in mice, resulting in reduced cold tolerance, and EODF ameliorates this age-related alteration (122). Mice subjected to 14 cycles of one day of fasting followed by two days of ad libitum feeding exhibited reduced energy expenditure in brown adipose tissue, an adaptation that may play a role in the conservation of energy during intermittent bouts of food deprivation (28). Adult male rats were maintained on an alternating schedule of three days fasting and three days refeeding for ten weeks, and several physiological responses to exercise were measured (37). In response to two hours of swimming, rats on the control diet exhibited hypoglycemia, whereas rats on the EODF diet were able to maintain blood glucose levels even though they had lower levels of liver glycogen and plasma free fatty acids. Thus, CR and intermittent fasting can enhance homeostatic mechanisms that counteract the potentially damaging effects of environmental stressors.

\section{DISEASE}

Overeating increases the risk of numerous diseases and shortens life span (13, 16). Accordingly, $\mathrm{CR}$ reduces disease risk in overweight individuals and may also have health benefits in those of normal weight (56). The influence of meal frequency on health and disease processes is not well known. However, studies of the physiological effects of long-term energy restriction and intermittent fasting in animals and humans are revealing possible mechanisms responsible for effects of meal size and frequency on health and disease processes.

\section{Cancer}

Studies of rodents have consistently shown that both CR and intermittent fasting can reduce the incidence of spontaneous tumors and can suppress the development and growth of induced cancers. When adult tumor-prone mice were maintained on either $40 \%$ energy restriction or a one-day-per-week fasting regimen, the onset 
of spontaneous tumors was significantly delayed (12). A "weight-cycling" regimen in which mice were fed a repeating cycle of three weeks at $50 \%$ of ad libitum intake followed by three weeks ad libitum during their adult life reduced both the incidence and latency of mammary tumors (20). When one-month-old Wistar rats were maintained on a schedule of $48 \mathrm{~h}$ of fasting per week for 48 weeks, they were more resistant to hepatocarcinogenesis induced by diethylnitrosamine compared with rats fed ad libitum (111). In another study, $40 \%$ energy restriction protected against carcinogen-induced tumor formation in mice, but an energy cycling diet (alternating two-day periods of $40 \%$ energy restriction and ad libitum feeding) was ineffective (55). CR also appears to decrease cancer incidence in monkeys (82). The mechanism by which energy restriction suppresses cancer formation may involve enhancement of apoptosis and inhibition of angiogenesis (98).

\section{Type 2 Diabetes}

The risk for type 2 diabetes is greatly increased by excessive weight gain attributable to long-term diets with energy intakes in excess of requirement (23), and $\mathrm{CR}$ is effective in improving glucose regulation in individuals with diabetes (135). Animal studies strongly support antidiabetic effects of CR and intermittent fasting diets. Both CR and EODF reduce blood glucose and insulin concentrations and improve glucose tolerance in rodents $(4,133,136)$. The issue of whether it is healthier to eat small frequent meals or less-frequent larger meals is currently the subject of considerable debate (85). Although it has been reported that patients with diabetes are better able to "control" their blood glucose concentrations when they eat regular small meals, an intermittent very-low-calorie diet improved weight loss and glycemic control more effectively than did moderate CR in subjects with type 2 diabetes (135). Moreover, two different fasting regimens (EODF and fasting two days per week) reduced diabetes incidence in Brattleboro rats (106). Increased insulin sensitivity appears to be the major mechanism responsible for the antidiabetic effects of energy restriction and intermittent fasting $(4,48)$.

\section{Cardiovascular Disease}

Data from epidemiological studies have shown that low-energy diets reduce the risk of cardiovascular disease and stroke in humans (3). A recent study in humans provided strong evidence that long-term $\mathrm{CR}$ can reduce the risk of atherosclerosis (39). In addition to suppressing the process of atherosclerosis, energy restriction and regular fasting may more directly protect heart and brain cells against ischemic damage. Indeed, CR protected the heart against myocardial infarction in rats (24). When rats were maintained for three months on EODF, the extent of brain damage following a stroke was decreased and functional outcome improved (144). Thus, $\mathrm{CR}$ and intermittent fasting can counteract the processes that, over long periods, 
result in occlusion of blood vessels, and may also improve outcome in those who suffer a myocardial infarction or stroke.

\section{Neurodegenerative and Psychiatric Disorders}

By comparison with the large amount of data suggesting that reduced energy intake and meal frequency can protect against diabetes, cardiovascular disease, and cancers, relatively little is known of the influence of meal size and frequency on neurological disorders. Age-related deficits in motor function and cognition can be prevented or delayed in mice and rats maintained on $30 \%-40 \%$ CR or EODF $(62,92)$. Diabetic and prediabetic women have impaired cognitive performance and greater risk of developing cognitive impairment (141). When mice were maintained on EODF, the dopaminergic neurons in their brains were protected against dysfunction and degeneration induced by the toxin MPTP (1-methyl-4-phenyl1,2,3,6-tetrahydropyridine), a model of Parkinson's disease (30). In a nonhuman primate model of Parkinson's disease, 30\% CR was effective in reducing the severity of symptoms (81). EODF and CR can protect hippocampal neurons and basal forebrain cholinergic neurons against death induced by excitotoxins (18, 22). EODF in rats protected hippocampal neurons against degeneration induced by the amnestic excitotoxin kainic acid; memory impairment was preserved in the intermittent-fasted rats compared to the control rats fed ad libitum (18). EODF was also beneficial in a mouse model of Huntington's disease, delaying the neurodegenerative process and motor dysfunction and increasing survival (31). In contrast to the neuroprotective effects of EODF in the just-mentioned brain disorder models, EODF was not beneficial in a mouse model of amyotrophic lateral sclerosis, a motor neuron disorder (107). Thus, the influence of meal size and frequency on the development and progression of neurodegenerative disorders may depend upon the specific disorder.

Accumulating data suggest that meal size and frequency can affect mental health. There is an increased prevalence of insulin resistance in patients with schizophrenia and chronic depression compared with the general population (124). Overweight and insulin resistance have also been associated with bipolar disorder (88). The explanation(s) for these relationships might simply be that subjects with psychiatric disorders eat more and exercise less. However, it is also possible that overeating is a contributing factor to the development of psychiatric disorders. The latter possibility is supported by studies showing that CR improves mood in obese subjects (137). The mechanisms by which CR and intermittent fasting might affect the risk of psychiatric disorders are unknown but might involve changes in neurotransmitters and neurotrophic factors (see "Cellular and Molecular Mechanisms" and "The Brain Mediates Health Effects of Dietary Excesses and Frugality" sections below). Anorexia nervosa and binge eating are psychiatric conditions that fall within a broader spectrum of obsessive-compulsive disorders (54). These disorders are associated with considerable morbidity and mortality, and provide examples of the existence of a lower limit of energy intake and upper limits of meal size that, if exceeded, lead to disease (36). 


\section{Other Diseases}

Meal size and frequency affect tissues throughout the body, and it is therefore not surprising that $\mathrm{CR}$ and fasting have been shown to influence disease processes in many different organ systems. Examples include the following. When mice and rats were maintained on CR during their adult life, the incidence of spontaneous cataracts was decreased (139). EODF improved renal function and reduced age-related glomerular lesions in rats (42). CR enhanced the regeneration of hepatocytes and prevented mortality in a rat model of liver injury (5). Patients with arthritis exhibited improved disease activity when they were maintained on CR (64). Considerable further work will be required to establish the full spectrum of diseases that may be subject to modification by energy intake and meal frequency.

\section{CELLULAR AND MOLECULAR MECHANISMS}

Studies of tissues from animals on CR and fasting diets have provided evidence for two major mechanisms by which meal size and frequency affect health and disease susceptibility. One mechanism involves the production and removal of free radicals, and the second involves stress resistance $(84,93,134)$. Overeating increases oxidative stress in cells throughout the body as indicated by lipid peroxidation and the accumulation of oxidatively damaged proteins and DNA. Conversely, the amount of oxidative damage to cellular proteins, lipids, and nucleic acids is decreased in various tissues of rodents on CR (87). The vulnerability of cells to being damaged and killed by oxidative insults (radiation, mitochondrial toxins, ischemia, iron, etc.) is decreased in animals maintained on CR or EODF diets (18, $30,40,68)$. CR and EODF may suppress oxidative stress by reducing the amount of superoxide anion radical produced in the mitochondria and by stimulating the expression of genes that encode antioxidant enzymes and protein chaperones (49, 120).

When meal size and frequency are decreased in rats and mice, they become more resistant to being killed by severe stresses including exposure to toxins and high temperatures $(5,53,119)$. Mice that had been maintained on EODF for one to six weeks exhibited increased resistance to death induced by gamma irradiation; the protective effect became maximal after two to three weeks of EODF (69). The stress resistance is manifest at the cellular level. For example, neurons in the brains of animals on CR and EODF diets exhibit increased resistance to being killed by neurotoxins $(18,22,30)$, and heart and brain cells are more resistant to ischemic injury $(1,144)$.

Analyses of gene expression (and levels of the encoded proteins) reveal that CR and EODF increase the production of multiple cell survival-promoting proteins in tissues ranging from liver to brain. The stress proteins induced include protein chaperones such as heat-shock protein 70 and glucose-regulated protein 78 ( 30 , $58,144)$ and growth factors such as brain-derived neurotrophic factor (BDNF) and glial cell line-derived neurotrophic factor (GDNF) $(31,72,81)$. The ability of cells 


\section{Energy restriction Intermittent fasting 1 \\ Signal transduction \\ Growth factors (IGFs, BDNF, GDNF) \\ Neurotransmitters (glutamate, serotonin) \\ Calcium influx

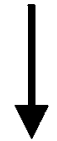 \\ Gene expression \\ Stress resistance proteins (HSP-70, GRP-78) \\ Antioxidants (SODs, GSH) \\ Energy metabolism enzymes (ETC and glycolysis)

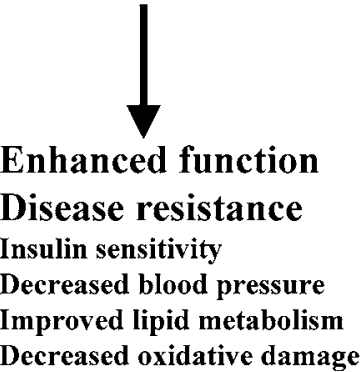

Figure 2 Mechanisms by which reduced energy intake and meal frequency may protect against disease. Dietary restriction results in the activation of signaling pathways that stimulate the expression of genes that encode proteins that help cells cope with stress and resist disease. BDNF, brain-derived neurotrophic factor; ETC, electron transport chain; GDNF, glial cell line-derived neurotrophic factor; GRP-78, glucoseregulated protein 78; GSH, glutathione; HSP-70, heat-shock protein 70; IGFs, insulinlike growth factors; SOD, superoxide dismutase.

to activate a stress response is enhanced in animals that have been maintained on CR $(26,58)$. Such enhanced stress resistance has been proposed as a major mechanism whereby energy restriction and intermittent fasting increase life span (Figure 2). On the other hand, overeating may foster disease by reducing the ability of cells to activate stress-resistance pathways. Recent studies of organisms from yeast to mammals have identified proteins called sirtuins (a type of histone deacetylase) that can increase cellular stress resistance and may be key mediators of the life span-extending effects of CR. For example, in rats, the sirtuin SIRT1 is induced by $\mathrm{CR}$, and it increases the resistance of cells to stress-induced death (21). 


\section{THE BRAIN MEDIATES HEALTH EFFECTS OF DIETARY FRUGALITY AND EXCESSES}

The brain evolved as the major regulator of food acquisition and energy metabolism (83). By direct innervation, and indirectly through the regulation of neuroendocrine systems, the brain controls the function and homeostasis of tissues and organs throughout the body. The brain is responsible for the behaviors involved in the identification and ingestion of food, and it regulates energy allocation and usage in various organs. The importance of the brain in energy regulation is underscored by its ability to perceive signals regarding energy intake and availability from peripheral organs and to modify behavior and cellular metabolism in adaptive ways. Nuclear magnetic resonance spectroscopy was used to measure adnosine triphosphate and phospocreatine levels in brain and liver of rats in the fasting and fed states and during intermittent feeding (14). The brain itself, in contrast to the liver, is able to maintain energy metabolism regardless of whether energy is supplied intermittently or continuously. The preservation of brain energy metabolism, at the expense of some peripheral tissues, is critical for the organism's ability to find food and replenish energy reserves.

The brain is also the master regulator of stress responses, which involve sensory inputs, and activation of neuroendocrine pathways involving the hypothalamus, which produces corticotrophin-releasing hormone, and the pituitary gland, which produces adrenocorticotrophin. Adrenocorticotrophin, in turn, stimulates production of glucocorticoids (cortisol in primates and corticosterone in rodents) in adrenocortical cells. Interestingly, basal levels of glucocorticoids are increased by $\mathrm{CR}$ and EODF, consistent with a mild stress response stimulated by such restricted diets $(105,130)$. It appears that the brain's perception of CR and intermittent fasting as stressors is central to activation of stress-resistance mechanisms that may protect against disease (11).

Lat \& Holeckova (71) provided evidence that intermittent fasting results in increased excitability of the CNS. CR may reduce, and overeating increases, activity of the sympathetic nervous system, which likely contributes the opposite effects of CR and overeating on blood pressure (143). Levels of beta-adrenergic receptors increase in the liver during aging in rats fed ad libitum, but not in rats on EODF (25). The increased activity in nerve cell circuits in animals on energy restriction or intermittent fasting likely contributes to several beneficial effects of the reduced meal size and frequency within the brain. For example, CR and EODF enhance learning and memory ability in rodents (62). The production of new nerve cells in the brain is also influenced by meal size and frequency. The adult mammalian brain contains populations of self-renewing stem cells that are capable of forming new neurons and glial cells. EODF increases the survival of newly generated neurons in the dentate gyrus of the hippocampus in adult mice (72). On the other hand, CR did not increase hippocampal neurogenesis, but did enhance glial cell genesis by increasing the survival of newly generated glial cells (15). 


\section{BRAIN-DERIVED NEUROTROPHIC FACTOR}

$\mathrm{CR}$ and intermittent fasting may affect health by activating signal transduction pathways in the brain that exert effects not only in the brain itself, but also in the periphery. Recent studies have shown that EODF can stimulate the production of BDNF in neurons in many different brain regions $(31,72)$. Other studies have shown that BDNF is a very important neurotrophic factor that plays roles in feeding, learning and memory, locomotion, stress responses, and affective behaviors (108). BDNF promotes neuronal differentiation and survival, synaptogenesis, and synaptic plasticity $(43,73,114)$. BDNF may serve in adaptive responses of mammals to a variety of environmental stimuli because BDNF expression in the hippocampus increases in response to cognitive stimulation and EODF, but decreases under conditions of chronic uncontrollable stress $(86,89)$. Decreased BDNF levels occur in several neurodegenerative disorders including Alzheimer's, Parkinson's, and Huntington's diseases $(38,59,61)$. BDNF suppresses feeding and improves glucose metabolism, as demonstrated in studies of BDNF $+/-$ mice $(32,76)$. When BDNF+/- mice are maintained on an EODF diet, levels of BDNF increase in their brains and blood glucose levels and body weights are normalized (32).

The increased level of BDNF in the brain with regular exercise and intermittent fasting may be important in the improved glucose regulation because intracerebroventricular infusion of BDNF can increase peripheral insulin sensitivity in normal rodents (100) and ameliorates diabetes in mice (101). Moreover, mice in which BDNF was eliminated from the brain after birth were hypersensitive to stress, had elevated plasma glucose and insulin levels, and were obese (110). Thus, EODF and exercise enhance BDNF signaling, which, in turn, may stimulate signaling pathways that improve glucose metabolism and increase cellular stress resistance, thereby protecting against several different diseases.

\section{Serotonin}

Serotonin (5-hydroxytryptamine) is an evolutionarily conserved neurotransmitter that regulates the development and function of the mammalian brain and serves important roles in the regulation of energy metabolism in diverse organisms (7, 125). Serotonergic neurons in the raphe nucleus of the brain stem possess axons that form synapses in many different brain regions. Serotonin activates receptors coupled to GTP-binding proteins, most notably those that activate adenylate cyclase resulting in cyclic AMP production. Studies in which serotonin signaling was manipulated using pharmacological agents have provided evidence for important roles for this neurotransmitter in learning and memory, appetite regulation, neurogenesis, and affective behaviors (17). Reductions in serotonin signaling occur in several prominent psychiatric disorders, including depression and anxiety disorders (126), and in neurodegenerative disorders such as Alzheimer's disease (96). 
Interestingly, serotonin may improve mood and protect neurons against degeneration by activating receptors coupled to cyclic AMP production and stimulation of BDNF production (114). BDNF, in turn, can enhance the survival and growth of serotonergic neurons (77).

Serotonin signaling can modify the risk of several major age-related disorders in both rodents and humans. Antidepressants that appear to act by increasing synaptic serotonin levels can improve risk factors for diabetes and cardiovascular disease. Patients with clinical depression have reduced insulin sensitivity compared with control subjects without depression, and the insulin sensitivity in the patients increases during treatment with serotonin-selective reuptake inhibitors (SSRIs) (103). Treatment with the SSRI paroxetine increased insulin sensitivity in depressed diabetic women (104), and when men with abdominal obesity were treated for six months with the SSRI citalopram, they showed improved glucose tolerance and their cardiovascular responses to stress were attenuated (74). Moreover, the disease process in the brain is suppressed and hyperglycemia is ameliorated by SSRI treatment in a murine model of Huntington's disease (33). The metabolic syndrome has been reported to be associated with suppressed neuroendocrine responses to serotonin (99), which suggests that a defect in serotonergic control of hypothalamic function may underlie the impaired ability of patients with insulin resistance to engage adaptive responses to stress.

Roles for serotonin in health effects of energy intake and meal frequency remain to be established. However, data are accumulating that suggest associations between food intake patterns, serotonin signaling, and disease risk. For example, using in vivo microdialysis methods, Gur et al. (50) provided evidence that serotonergic signaling is increased in the hypothalamus of female rats that had been maintained for four weeks on a food-restriction regimen. Serotonin turnover in the brain is affected by semi-starvation in rats, consistent with a role for this neurotransmitter in mediating responses to changes in meal frequency (118). Levels of serotonin are decreased in the brains of rats during aging, and treatment of the aged rats with the antioxidant alpha-lipoic acid increased serotonin levels, which suggests that serotonin depletion during aging may result, at least in part, from oxidative stress (6). These findings suggest that serotonin signaling in the brain can suppress a process, i.e., oxidative stress, which may be fundamental to the aging process. During normal aging in humans, levels of serotonin are relatively stable and levels of several serotonin receptors decrease; in contrast, patients with Alzheimer's disease exhibit degeneration of serotonergic neurons that, in combination with serotonin receptor loss, results in a severe functional serotonergic deficit (96). Positron emission tomography imaging of glucose metabolism in the brains of young and old control subjects and subjects treated with the SSRI citalopram suggests that age-related loss of serotonin innervation of the cerebral cortex can be compensated for in some brain regions (44). These kinds of data suggest a role for serotonin in aging and provide a rationale for direct tests of the effects of manipulations of serotonergic signaling on life span in rodents. 


\section{IMPLICATIONS FOR IMPROVING HEALTH}

What are the implications of the findings described in this article for improving health? The data from the animal studies reviewed above suggest that reducing energy intake and intermittent fasting can have numerous health benefits, effectively reducing morbidity and mortality. Most adults and many children in industrialized countries could clearly benefit from reducing energy intake by decreasing meal size. The problem is how to accomplish this in an environment of an overabundance of continuously accessible high-energy foods and beverages and in the face of unavoidable advertisements from the food industry. To date, the majority of people who overeat have been unable to voluntarily limit their food intake, despite their knowledge of the health hazards of overeating. Primary care physicians are not trained in diet management and are not prepared to prescribe specific eating regimens on a case-by-case basis. This is unfortunate, as overeating is a major health problem and should be treated as such. Beyond simply reducing the amount of food consumed, CR can be accomplished by substituting foods with a low energy density (vegetables and fruits) for those with a high energy density (fried foods, fatty meats, etc.). The latter approach has the added benefit of including foods that contain higher amounts of vitamins and various other beneficial phytochemicals.

What strategies and interventions might be implemented to take advantage of the health benefits of CR and intermittent fasting? Physicians are trained to deal with extreme overeating and anorexia, disorders that can be considered psychiatric disorders that result from abnormalities in brain neurochemistry and can be treated with behavioral therapy and medications $(128,132)$. In contrast, most practicing physicians are not trained to make recommendations regarding the health benefits of dietary restriction in individuals who are not obese. Medical students and residents should be trained in the physiology of dietary restriction and its value in disease prevention for most individuals. Controlled human studies should be performed in order to establish the parameters of meal frequency and energy intake that are optimal for reducing the risk of major diseases. Patients would then be prescribed a dietary regimen that would be expected to result in health benefits. Because of the strong links between insulin sensitivity and blood pressure to diabetes and cardiovascular disease, these variables could be monitored in individual patients as surrogate measures of disease risk. The limited data available from human studies of meal frequency suggest that if the subjects can adhere to an intermittent fasting regimen for at least 10-14 days, it thereafter becomes relatively easy to continue on the diet (57; M.P. Mattson, unpublished data).

For those who are unable or unwilling to reduce their food intake to improve their health, emerging evidence suggests that it may be possible to develop dietary supplements and drugs that induce energy restriction by influencing hunger and appetite (9) or by mimicking the effects of CR (63). For example, drugs that increase serotonin and BDNF levels should be effective, in principle, in suppressing food intake. However, the use of serotonin reuptake inhibitors in obese patients has had mixed results. Drugs that target hypothalamic neuropeptide signaling pathways 
that control appetite hold considerable promise for the treatment of overeating as well as for anorexia, and the development of such drugs is under way (52).

Finally, it may be possible to activate the same cellular and molecular pathways that occur in various tissues in response to $\mathrm{CR}$ and intermittent fasting. For example, some of these pathways, which result in increased cellular stress resistance, can be activated by physical exercise and cognitive stimulation (84). Animal studies suggest that $\mathrm{CR}$ and intermittent-fasting pathways might also be activated with dietary supplements and drugs. For example, dietary supplementation with 2-deoxy-D-glucose has been shown to induce beneficial physiological effects similar to CR and intermittent fasting $(63,131)$. Another approach is to activate sirtuins. Recent studies have shown that resveratrol stimulates sirtuins and can exert antiaging effects at the cellular level; interestingly, resveratrol is thought to be a chemical responsible for the health benefits of consumption of red wine $(70,117)$. However, the long-term safety of such pharmacological approaches remains to be established. Nevertheless, future advances in understanding the mechanisms by which energy intake and meal frequency affect health and disease processes will lead to novel approaches for increasing both the quality and quantity of our lives.

\section{The Annual Review of Nutrition is online at http://nutr.annualreviews.org}

\section{LITERATURE CITED}

1. Abete P, Testa G, Ferrara N, De Santis D, Capaccio P. 2002. Cardioprotective effect of ischemic preconditioning is preserved in food-restricted senescent rats. Am. $J$. Physiol. Heart Circ. Physiol. 282:H197887

2. Adlouni A, Ghalim N, Benslimane A, Lecerf JM, Saile R. 1997. Fasting during Ramadan induces a marked increase in high-density lipoprotein cholesterol and decrease in low-density lipoprotein cholesterol. Ann. Nutr. Metab. 41:242-49

3. Altmann J, Kornhuber AW, Kornhuber HH. 1987. Stroke: cardiovascular risk factors and the quantitative effects of dietary treatment on them. Eur. Neurol. 26:90-99

4. Anson RM, Guo Z, de Cabo R, Iyun T, Rios $M$, et al. 2003. Intermittent fasting dissociates beneficial effects of dietary restriction on glucose metabolism and neuronal resistance to injury from calorie intake. Proc. Natl. Acad. Sci. USA 100:6216-20

5. Apte UM, Limaye PB, Desaiah D, Bucci
TJ, Warbritton A, Mehendale HM. 2003. Mechanisms of increased liver tissue repair and survival in diet-restricted rats treated with equitoxic doses of thioacetamide. Toxicol. Sci. 72:272-82

6. Arivazhagan P, Panneerselvam C. 2002. Neurochemical changes related to ageing in the rat brain and the effect of DL-alphalipoic acid. Exp. Gerontol. 37:1489-94

7. Azmitia EC. 2001. Modern views on an ancient chemical: serotonin effects on cell proliferation, maturation, and apoptosis. Brain Res. Bull. 56:413-24

8. Bates GW, Bates SR, Whitworth NS. 1982. Reproductive failure in women who practice weight control. Fertil. Steril. 37:373-78

9. Bays H, Dujovne C. 2002. Pharmacotherapy of obesity: currently marketed and upcoming agents. Am. J. Cardiovasc. Drugs 2:245-53

10. Beauchene RE, Bales CW, Bragg CS, Hawkins ST, Mason RL. 1986. Effect of age of initiation of feed restriction on 
growth, body composition, and longevity of rats. J. Gerontol. 41:13-19

11. Berner YN, Stern F. 2004. Energy restriction controls aging through neuroendocrine signal transduction. Ageing Res. Rev. 3:189-98

12. Berrigan D, Perkins SN, Haines DC, Hursting SD. 2002. Adult-onset calorie restriction and fasting delay spontaneous tumorigenesis in p53-deficient mice. Carcinogenesis 23:817-22

13. Bianchini F, Kaaks R, Vainio H. 2002. Overweight, obesity, and cancer risk. Lancet Oncol. 3:565-74

14. Bodoky G, Yang ZJ, Meguid MM, Laviano A, Szeverenyi N. 1995. Effects of fasting, intermittent feeding, or continuous parenteral nutrition on rat liver and brain energy metabolism as assessed by ${ }^{31}$ P-NMR. Physiol. Behav. 58:521-27

15. Bondolfi L, Ermini F, Long JM, Ingram DK, Jucker M. 2004. Impact of age and caloric restriction on neurogenesis in the dentate gyrus of C57BL/6 mice. Neurobiol. Aging 25:333-40

16. Bray GA. 2004. Medical consequences of obesity. J. Clin. Endocrinol. Metab. 89:2583-89

17. Brezun JM, Daszuta A. 1999. Depletion in serotonin decreases neurogenesis in the dentate gyrus and the subventricular zone of adult rats. Neuroscience 89:999-1002

18. Bruce-Keller AJ, Umberger G, McFall R, Mattson MP. 1999. Food restriction reduces brain damage and improves behavioral outcome following excitotoxic and metabolic insults. Ann. Neurol. 45:815

19. Carlson AJ, Hoelzel F. 1946. Apparent prolongation of the life span of rats by intermittent fasting. J. Nutr. 31:363-77

20. Cleary MP, Jacobson MK, Phillips FC, Getzin SC, Grande JP, Maihle NJ. 2002. Weight-cycling decreases incidence and increases latency of mammary tumors to a greater extent than does chronic caloric restriction in mouse mammary tumor virus-transforming growth factor-alpha female mice. Cancer Epidemiol. Biomarkers Prev. 11:836-43

21. Cohen HY, Miller C, Bitterman KJ, Wall NR, Hekking B, et al. 2004. Calorie restriction promotes mammalian cell survival by inducing the SIRT1 deacetylase. Science 305:390-92

22. Contestabile A, Ciani E, Contestabile A. 2004. Dietary restriction differentially protects from neurodegeneration in animal models of excitotoxicity. Brain Res. 1002:162-66

23. Costacou T, Mayer-Davis EJ. 2003. Nutrition and prevention of type 2 diabetes. Annu. Rev. Nutr. 23:147-70

24. Crandall DL, Feirer RP, Griffith DR, Beitz DC. 1981. Relative role of caloric restriction and exercise training upon susceptibility to isoproterenol-induced myocardial infarction in male rats. Am. J. Clin. Nutr. 34:841-47

25. Dax EM, Ingram DK, Partilla JS, Gregerman RI. 1989. Food restriction prevents an age-associated increase in rat liver beta-adrenergic receptors. J. Gerontol. 44:B72-76

26. de Cabo R, Furer-Galban S, Anson RM, Gilman C, Gorospe M, Lane MA. 2003. An in vitro model of caloric restriction. Exp. Gerontol. 38:631-39

27. de los Santos-Arteaga M, SierraDominguez SA, Fontanella GH, DelgadoGarcia JM, Carrion AM. 2003. Analgesia induced by dietary restriction is mediated by the kappa-opioid system. J. Neurosci. 23:11120-26

28. Desautels M, Dulos RA. 1988. Effects of repeated cycles of fasting-refeeding on brown adipose tissue composition in mice. Am. J. Physiol. 255:E120-28

29. Dong W, Kari FW, Selgrade MK, Gilmour MI. 2000. Attenuated allergic responses to house dust mite antigen in feedrestricted rats. Environ. Health Perspect. 108:1125-31

30. Duan W, Mattson MP. 1999. Dietary restriction and 2-deoxyglucose administration improve behavioral outcome and 
reduce degeneration of dopaminergic neurons in models of Parkinson's disease. $J$. Neurosci. Res. 57:195-206

31. Duan W, Guo Z, Jiang H, Ware M, Li XJ, Mattson MP. 2003. Dietary restriction normalizes glucose metabolism and BDNF levels, slows disease progression, and increases survival in huntingtin mutant mice. Proc. Natl. Acad. Sci. USA 100:2911-16

32. Duan W, Guo Z, Jiang H, Ware M, Mattson MP. 2003. Reversal of behavioral and metabolic abnormalities, and insulin resistance syndrome, by dietary restriction in mice deficient in brainderived neurotrophic factor. Endocrinology 144:2446-53

33. Duan W, Guo Z, Jiang H, Ladenheim B, $\mathrm{Xu} \mathrm{X}$, et al. 2004. Paroxetine retards disease onset and progression in huntingtin mutant mice. Ann. Neurol. 55:590-94

34. Duncan GG, Jenson WE, Fraser RI, Cristofori FC. 1962. Correction and control of intractable obesity. Practicable application of intermittent periods of total fasting. JAMA 181:309-12

35. Fabry P, Heil Z, Fodor J, Braun T, Zvolankova K. 1964. The frequency of meals and its relation to overweight, hypercholesterolemia and decreased glucose tolerance. Lancet 18:614-15

36. Fairburn CG, Harrison PJ. 2003. Eating disorders. Lancet 361:407-16

37. Favier RJ, Koubi HE. 1988. Metabolic and structural adaptations to exercise in chronic intermittent fasted rats. Am. J. Physiol. 254:R877-84

38. Ferrer I, Goutan E, Marin C, Rey MJ, Ribalta T. 2000. Brain-derived neurotrophic factor in Huntington disease. Brain Res. 866:257-61

39. Fontana L, Meyer TE, Klein S, Holloszy JO. 2004. Long-term calorie restriction is highly effective in reducing the risk for atherosclerosis in humans. Proc. Natl. Acad. Sci. USA 101:6659-63

40. Frame LT, Hart RW, Leakey JE. 1998. Caloric restriction as a mechanism medi- ating resistance to environmental disease. Environ. Health Perspect. 106:S313-24

41. Gat-Yablonski G, Ben-Ari T, Shtaif B, Potievsky O, Moran O, et al. 2004. Leptin reverses the inhibitory effect of caloric restriction on longitudinal growth. Endocrinology 145:343-50

42. Gehrig JJ Jr, Ross J, Jamison RL. 1988. Effect of long-term, alternate day feeding on renal function in aging conscious rats. Kidney Int. 34:620-30

43. Ghosh A. 1994. Requirement for BDNF in activity-dependent survival of cortical neurons. Science 263:1618-23

44. Goldberg S, Smith GS, Barnes A, Ma Y, Kramer E, et al. 2004. Serotonin modulation of cerebral glucose metabolism in normal aging. Neurobiol. Aging 25:16774

45. Goodrick CL, Ingram DK, Reynolds MA, Freeman JR, Cider NL. 1982. Effects of intermittent feeding upon growth and life span in rats. Gerontology 28:233-41

46. Goodrick CL, Ingram DK, Reynolds MA, Freeman JR, Cider NL. 1983. Effects of intermittent feeding upon growth, activity, and lifespan in rats allowed voluntary exercise. Exp. Aging Res. 9:203-09

47. Goodrick CL, Ingram DK, Reynolds MA, Freeman JR, Cider NL. 1990. Effects of intermittent feeding upon body weight and lifespan in inbred mice: interaction of genotype and age. Mech. Ageing Dev. 55:69-87

48. Granberry MC, Fonseca VA. 1999. Insulin resistance syndrome: options for treatment. South. Med. J. 92:2-15

49. Guo Z, Ersoz A, Butterfield DA, Mattson MP. 2000. Beneficial effects of dietary restriction on cerebral cortical synaptic terminals: preservation of glucose and glutamate transport and mitochondrial function after exposure to amyloid beta-peptide, iron, and 3-nitropropionic acid. J. Neurochem. 75:314-20

50. Gur E, Newman ME, Avraham Y, Dremencov E, Berry EM. 2003. The differential effects of food restriction on 
5-HT1A and 5-HT1B receptor mediated control of serotonergic transmission in the hippocampus and hypothalamus of rats. Nutr. Neurosci. 6:169-75

51. Hales CN, Ozanne SE. 2003. The dangerous road of catch-up growth. J. Physiol. 547:5-10

52. Halford JC, Cooper GD, Dovey TM. 2004. The pharmacology of human appetite expression. Curr. Drug Targets 5:221-40

53. Hall DM, Oberley TD, Moseley PM, Buettner GR, Oberley LW, et al. 2000. Caloric restriction improves thermotolerance and reduces hyperthermia-induced cellular damage in old rats. FASEB $J$. 14:78-86

54. Halmi KA, Sunday SR, Klump KL, Strober M, Leckman JF, et al. 2003. Obsessions and compulsions in anorexia nervosa subtypes. Int. J. Eat. Disord. 33:30819

55. Harris SR, Brix AE, Broderson JR, Bunce OR. 1995. Chronic energy restriction versus energy cycling and mammary tumor promotion. Proc. Soc. Exp. Biol. Med. 209:231-36

56. Heilbronn LK, Ravussin E. 2003. Calorie restriction and aging: review of the literature and implications for studies in humans. Am. J. Clin. Nutr. 78:361-69

57. Heilbronn LK, Smith SR, Martin CK, Anton S, Ravussin E. 2005. Alternateday fasting in nonobese subjects: effects on body weight, body composition, and energy metabolism. Am. J. Clin. Nutr. 81:69-73

58. Heydari AR, You S, Takahashi R, Gutsmann A, Sarge KD, Richardson A. 1996. Effect of caloric restriction on the expression of heat shock protein 70 and the activation of heat shock transcription factor 1. Dev. Genet. 18:114-24

59. Hock C, Heese K, Hulette C, Rosenberg C, Otten U. 2000. Region-specific neurotrophin imbalances in Alzheimer disease: decreased levels of brain-derived neurotrophic factor and increased levels of nerve growth factor in hippocampus and cortical areas. Arch. Neurol. 57:84651

60. Holeckova E, Chvapil M. 1965. The effect of intermittent feeding and fasting and of domestication on biological age in the rat. Gerontologia 11:96-119

61. Howells DW, Porritt MJ, Wong JY, Batchelor PE, Kalnins R, et al. 2000. Reduced BDNF mRNA expression in Parkinson's disease substantia nigra. Exp. Neurol. 166:127-35

62. Ingram DK, Weindruch R, Spangler EL, Freeman JR, Walford RL. 1987. Dietary restriction benefits learning and motor performance of aged mice. J. Gerontol. 42:78-81

63. Ingram DK, Anson RM, de Cabo R, Mamczarz J, Zhu M, et al. 2004. Development of calorie restriction mimetics as a prolongevity strategy. Ann. NY Acad. Sci. 1019:412-23

64. Iwashige K, Kouda K, Kouda M, Horiuchi K, Takahashi M, et al. 2004. Calorie restricted diet and urinary pentosidine in patients with rheumatoid arthritis. J. Physiol. Anthropol. Appl. Human Sci. 23:1924

65. Jenkins JD, Wolever TM, Vuksan V, Brighenti F, Cunnane SC, et al. 1989. Nibbling versus gorging: metabolic advantages of increased meal frequency. $N$. Engl. J. Med. 321:929-34

66. Keski-Rahkonen A, Kaprio J, Rissanen A, Virkkunen M, Rose RJ. 2003. Breakfast skipping and health-compromising behaviors in adolescents and adults. Eur. J. Clin. Nutr. 57:842-53

67. Keys A. 1994. 1944 symposium on convalescence and rehabilitation. FASEB $J$. 8:1201-2

68. Kim KY, Ju WK, Neufeld AH. 2004. Neuronal susceptibility to damage: comparison of the retinas of young, old and old/caloric restricted rats before and after transient ischemia. Neurobiol. Aging 25:491-500

69. Kozubik A, Pospisil M. 1982. Protective 
effect of intermittent fasting on the mortality of gamma-irradiated mice. Strahlentherapie 158:734-38

70. Lamming DW, Wood JG, Sinclair DA. 2004. Small molecules that regulate lifespan: evidence for xenohormesis. Mol. Microbiol. 53:1003-9

71. Lat J, Holeckova E. 1971. The effect of intermittent feeding and fasting on the nonspecific excitability level of the central nervous system in the rat. Physiol. Bohemoslov. 20:441-45

72. Lee J, Duan W, Mattson MP. 2002. Evidence that brain-derived neurotrophic factor is required for basal neurogenesis and mediates, in part, the enhancement of neurogenesis by dietary restriction in the hippocampus of adult mice. J. Neurochem. 82:1367-75

73. Lindsay RM. 1994. Neurotrophins and receptors. Prog. Brain Res. 103:3-14

74. Ljung T, Ahlberg AC, Holm G, Friberg P, Andersson B, et al. 2001. Treatment of abdominally obese men with a serotonin reuptake inhibitor: a pilot study. J. Intern. Med. 250:219-24

75. London ED, Waller SB, Ellis AT, Ingram DK. 1985. Effects of intermittent feeding on neurochemical markers in aging rat brain. Neurobiol. Aging 6:199-204

76. Lyons WE, Mamounas LA, Ricaurte GA, Coppola V, Reid SW, et al. 1999. Brain-derived neurotrophic factordeficient mice develop aggressiveness and hyperphagia in conjunction with brain serotonergic abnormalities. Proc. Natl. Acad. Sci. USA 96:15239-44

77. Mamounas LA, Blue ME, Siuciak JA, Altar CA. 1995. Brain-derived neurotrophic factor promotes the survival and sprouting of serotonergic axons in rat brain. $J$. Neurosci. 15:7929-39

78. Mann PL. 1978. The effect of various dietary restricted regimes on some immunological parameters of mice. Growth 42:87-103

79. Marcos A, Varela P, Santacruz I, MunozVelez A, Morande G. 1993. Nutritional status and immunocompetence in eating disorders. A comparative study. Eur. J. Clin. Nutr. 47:787-93

80. Martin A, Normand S, Sothier M, Peyrat J, Louche-Pelissier C, Laville M. 2000. Is advice for breakfast consumption justified? Results from a short-term dietary and metabolic experiment in young healthy men. Br. J. Nutr. 84:337-44

81. Maswood N, Young J, Tilmont E, Zhang Z, Gash DM, et al. 2004. Caloric restriction increases GDNF levels and attenuates neurochemical and behavioral deficits in a primate model of Parkinson's disease. Proc. Natl. Acad. Sci. USA 101:1817176

82. Mattison JA, Lane MA, Roth GS, Ingram DK. 2003. Calorie restriction in rhesus monkeys. Exp. Gerontol. 38:35-46

83. Mattson MP. 2002. Brain evolution and lifespan regulation: conservation of signal transduction pathways that regulate energy metabolism. Mech. Aging Dev. 123:947-53

84. Mattson MP. 2003. Gene-diet interactions in brain aging and neurodegenerative disorders. Ann. Intern. Med. 139:441-44

85. Mattson MP. 2005. The need for controlled studies of the effects of meal frequency on health. Lancet 365:In press

86. Mattson MP, Chan SL, Duan W. 2002. Modification of brain aging and neurodegenerative disorders by genes, diet, and behavior. Physiol. Rev. 82:637-72

87. McCay CM, Crowell MF, Maynard LA. 1989. The effect of retarded growth upon the length of life span and upon the ultimate body size. Nutrition 5:155-71

88. McElroy SL, Kotwal R, Malhotra S, Nelson EB, Keck PE, Nemeroff CB. 2004. Are mood disorders and obesity related? A review for the mental health professional. J. Clin. Psychiatry 65:634-51

89. McEwen BS. 2002. Sex, stress and the hippocampus: allostasis, allostatic load and the aging process. Neurobiol. Aging 23:921-39

90. McGuire MK, Littleton AW, Schulze KJ, 
Rasmussen KM. 1995. Pre- and postweaning food restrictions interact to determine reproductive success and milk volume in rats. J. Nutr. 125:2400-6

91. McShane TM, Wise PM. 1996. Lifelong moderate caloric restriction prolongs reproductive life span in rats without interrupting estrous cyclicity: effects on the gonadotropin-releasing hormone/ luteinizing hormone axis. Biol. Reprod. 54:70-75

92. Means LW, Higgins JL, Fernandez TJ. 1993. Mid-life onset of dietary restriction extends life and prolongs cognitive functioning. Physiol. Behav. 54:503-8

93. Merry BJ. 2004. Oxidative stress and mitochondrial function with aging - the effects of calorie restriction. Aging Cell 3:712

94. Miller J, Rosenbloom A, Silverstein J. 2004. Childhood obesity. J. Clin. Endocrinol. Metab. 89:4211-18

95. Miller KK, Grinspoon S, Gleysteen S, Grieco KA, Ciampa J, et al. 2004. Preservation of neuroendocrine control of reproductive function despite severe undernutrition. J. Clin. Endocrinol. Metab. 89:4434-38

96. Morgan DG, May PC, Finch CE. 1987. Dopamine and serotonin systems in human and rodent brain: effects of age and neurodegenerative disease. J. Am. Geriatr. Soc. 35:334-45

97. Moroi-Fetters SE, Mervis RF, London ED, Ingram DK. 1989. Dietary restriction suppresses age-related changes in dendritic spines. Neurobiol. Aging 10:31722

98. Mukherjee P, Abate LE, Seyfried TN. 2004. Antiangiogenic and proapoptotic effects of dietary restriction on experimental mouse and human brain tumors. Clin. Cancer Res. 10:5622-29

99. Muldoon MF, Mackey RH, Williams KV, Korytkowski MT, Flory JD, Manuck SB. 2004. Low central nervous system serotonergic responsivity is associated with the metabolic syndrome and physical in- activity. J. Clin. Endocrinol. Metab. 89: 266-71

100. Nakagawa T, Ono-Kishino M, Sugara E, Yamanaka M, Taiji M, Noguchi $\mathrm{H}$. 2002. Brain-derived neurotrophic factor (BDNF) regulates glucose and energy metabolism in diabetic mice. Diabetes Metab. Res. Rev. 18:185-91

101. Nakagawa T, Tsuchida A, Itakura Y, Nonomura T, Ono M, et al. 2000. Brain-derived neurotrophic factor regulates glucose metabolism by modulating energy balance in diabetic mice. Diabetes 49:436-44

102. Nicklas TA, Morales M, Linares A, Yang SJ, Baranowski T, et al. 2004. Children's meal patterns have changed over a 21-year period: the Bogalusa Heart Study. J. Am. Diet. Assoc. 104:753-61

103. Okamura F, Tashiro A, Utumu A, Imai T, Suchi T, et al. 2000. Insulin resistance in patients with depression and its changes during the clinical course of depression: minimal model analysis. Metabolism 49:1255-60

104. Paile-Hyvarinen M, Wahlbeck K, Eriksson JG. 2003. Quality of life and metabolic status in mildly depressed women with type 2 diabetes treated with paroxetine: a single-blind randomised placebo controlled trial. BMC Fam. Pract. 4:7

105. Patel NV, Finch CE. 2002. The glucocorticoid paradox of restriction in slowing brain aging. Neurobiol. Aging 23:70717

106. Pedersen CR, Hagemann I, Bock T, Buschard K. 1999. Intermittent feeding and fasting reduces diabetes incidence in BB rats. Autoimmunity 30:243-50

107. Pedersen WA, Mattson MP. 1999. No benefit of dietary restriction on disease onset or progression in ALS Cu/Zn-SOD mutant mice. Brain Res. 833:117-20

108. Reusens B, Remacle C. 2001. Intergenerational effect of an adverse intrauterine environment on perturbation of glucose metabolism. Twin Res. 4:406-11

109. Reynolds LK, Ho HP, Taper LJ. 1984. 
Effect of caloric restriction during pregnancy on maternal and fetal body composition in the obese Sprague-Dawley rat. $J$. Nutr. 114:2247-55

110. Rios M, Fan G, Fekete C, Kelly J, Bates B, et al. 2001. Conditional deletion of brainderived neurotrophic factor in the postnatal brain leads to obesity and hyperactivity. Mol. Endocrinol. 15:1748-57

111. Rocha NS, Barbisan LF, de Oliveira ML, de Camargo JL. 2002. Effects of fasting and intermittent fasting on rat hepatocarcinogenesis induced by diethylnitrosamine. Teratog. Carcinog. Mutagen. 22:129-38

112. Roky R, Houti I, Moussamih S, Qotbi S, Aadil N. 2004. Physiological and chronobiological changes during Ramadan intermittent fasting. Ann. Nutr. Metab. 48:296303

113. Roth GS, Mattison JA, Ottinger MA, Chachich ME, Lane MA, Ingram DK. 2004. Aging in rhesus monkeys: relevance to human health interventions. Science 305:1423-26

114. Russo-Neustadt A. 2003. Brain-derived neurotrophic factor, behavior, and new directions for the treatment of mental disorders. Semin. Clin. Neuropsychiatry 8:109-18

115. Sakamoto K, Grunewald KK. 1987. Beneficial effects of exercise on growth of rats during intermittent fasting. J. Nutr. 117:390-95

116. Santos AM, Ferraz MR, Teixeira CV, Sampaio FJ, da Fonte Ramos C. 2004. Effects of undernutrition on serum and testicular testosterone levels and sexual function in adult rats. Horm. Metab. Res. $36: 27-33$

117. Sardi B. 2004. The Anti-Aging Pill. San Dimas, CA: Here \& Now Books. 189 pp.

118. Schweiger U, Broocks A, Tuschl RJ, Pirke KM. 1989. Serotonin turnover in rat brain during semistarvation with high-protein and high-carbohydrate diets. J. Neural Transm. 77:131-39

119. Shaikh ZA, Jordan SA, Tang W. 1999.
Protection against chronic cadmium toxicity by caloric restriction. Toxicology 133:93-103

120. Sreekumar R, Unnikrishnan J, Fu A, Nygren J, Short KR, et al. 2002. Effects of caloric restriction on mitochondrial function and gene transcripts in rat muscle. Am. J. Physiol. Endocrinol. Metab. 283:E38-43

121. Stewart WK, Fleming LW, Robertson PC. 1966. Massive obesity treated by intermittent fasting. A metabolic and clinical study. Am. J. Med. 40:967-86

122. Talan MI, Ingram DK. 1985. Effect of intermittent feeding on thermoregulatory abilities of young and aged C57BL/6J mice. Arch. Gerontol. Geriatr. 4:251-59

123. Tanaka S, Inoue S, Isoda F, Waseda M, Ishihara M, et al. 1993. Impaired immunity in obesity: suppressed but reversible lymphocyte responsiveness. Int. J. Obes. Relat. Metab. Disord. 17:631-36

124. Toalson P, Ahmed S, Hardy T, Kabinoff G. 2004. The metabolic syndrome in patients with severe mental illnesses. Prim. Care Companion J. Clin. Psychiatry 6:152-58

125. Van Kesteren RE, Spencer GE. 2003. The role of neurotransmitters in neurite outgrowth and synapse formation. $\mathrm{Rev}$. Neurosci. 14:217-31

126. Vaswani M, Linda FK, Ramesh S. 2003. Role of selective serotonin reuptake inhibitors in psychiatric disorders: a comprehensive review. Prog. Neuropsychopharmacol. Biol. Psychiatry 27:85102

127. Vega VL, De Cabo R, De Maio A. 2004. Age and caloric restriction diets are confounding factors that modify the response to lipopolysaccharide by peritoneal macrophages in C57BL/6 mice. Shock 22:248-53

128. Wadden TA, Butryn ML. 2003. Behavioral treatment of obesity. Endocrinol. Metab. Clin. North Am. 32:981-1003

129. Walford RL, Mock D, Verdery R, MacCallum T. 2002. Calorie restriction in 
Biosphere 2: alterations in physiologic, hematologic, hormonal, and biochemical parameters in humans restricted for a 2year period. J. Gerontol. A Biol. Sci. Med. Sci. 57:B211-24

130. Wan R, Camandola S, Mattson MP. 2003. Intermittent food deprivation improves cardiovascular and neuroendocrine responses to stress in rats. J. Nutr. 133: 1921-29

131. Wan R, Camandola S, Mattson MP. 2004. Dietary supplementation with 2-deoxyD-glucose improves cardiovascular and neuroendocrine stress adaptation in rats. Am. J. Physiol. Heart Circ. Physiol. 287: H1186-93

132. Wang GJ, Volkow ND, Thanos PK, Fowler JS. 2004. Similarity between obesity and drug addiction as assessed by neurofunctional imaging: a concept review. $J$. Addict. Dis. 23:39-53

133. Wang ZO, Bell-Farrow AD, Sonntag W, Cefalu WT. 1997. Effect of age and caloric restriction on insulin receptor binding and glucose transporter levels in aging rats. Exp. Gerontol. 32:671-84

134. Weindruch R, Sohal RS. 1997. Seminars in medicine of the Beth Israel Deaconess Medical Center. Caloric intake and aging. N. Engl. J. Med. 337:986-94

135. Williams KV, Mullen ML, Kelley DE, Wing RR. 1998. The effect of short periods of caloric restriction on weight loss and glycemic control in type 2 diabetes. Diabetes Care 21:2-8

136. Wing RR, Blair EH, Bononi P, Marcus MD, Watanabe R, Bergman RN. 1994. Caloric restriction per se is a significant factor in improvements in glycemic control and insulin sensitivity during weight loss in obese NIDDM patients. Diabetes Care 17:30-36
137. Wing RR, Marcus MD, Blair EH, Burton LR. 1991. Psychological responses of obese type II diabetic subjects to verylow-calorie diet. Diabetes Care 14:59699

138. Wingard DL, Berkman LF, Brand RJ. 1982. A multivariate analysis of healthrelated practices: a nine-year mortality follow-up of the Alameda County Study. Am. J. Epidemiol. 116:765-75

139. Wolf NS, Li Y, Pendergrass W, Schmeider C, Turturro A. 2000. Normal mouse and rat strains as models for age-related cataract and the effect of caloric restriction on its development. Exp. Eye Res. 70:683-92

140. Wu A, Wan F, Sun X, Liu Y. 2002. Effects of dietary restriction on growth, neurobehavior, and reproduction in developing Kunmin mice. Toxicol Sci. 70:23844

141. Yaffe K, Blackwell T, Kanaya AM, Davidowitz N, Barrett-Connor E, Krueger K. 2004. Diabetes, impaired fasting glucose, and development of cognitive impairment in older women. Neurology 63:65863

142. Young JB, Mullen D, Landsberg L. 1978. Caloric restriction lowers blood pressure in the spontaneously hypertensive rat. Metabolism 27:1711-14

143. Young JB, Landsberg L. 1982. Dietinduced changes in sympathetic nervous system activity: possible implications for obesity and hypertension. J. Chronic Dis. 35:879-86

144. Yu ZF, Mattson MP. 1999. Dietary restriction and 2-deoxyglucose administration reduce focal ischemic brain damage and improve behavioral outcome: evidence for a preconditioning mechanism. J. Neurosci. Res. 57:830-39 
R Annual Review of Nutrition

Volume 25, 2005

\section{CONTENTS}

DIETARY FIBER: How DiD We GET WhERE We ARE?, Martin Eastwood and David Kritchevsky

Defective Glucose Homeostasis DuRING INFECTION, Owen P. McGuinness

Human Milk Glycans Protect Infants Against EnTERiC

PATHOGENS, David S. Newburg, Guillermo M. Ruiz-Palacios, and Ardythe L. Morrow

NUTRITIONAL CONTROL OF GENE EXPRESSION: HOW MAMMALIAN CELls ReSPOND to AMINO ACID LimitATION, M.S. Kilberg, Y.-X. Pan, H. Chen, and V. Leung-Pineda

MECHANISMS OF DigESTION AND ABSORPTION OF DIETARY VITAMIN A, Earl H. Harrison

REgUlation OF VITAMIN C TRANSPORT, John X. Wilson

ThE VitAMIN K-DEPENDENT CARBOXYLASE, Kathleen L. Berkner

Vitamin E, OXIDATIVE STRESS, AND INFLAMmation, $U$. Singh, S. Devaraj, and Ishwarlal Jialal

UPTAKE, LOCALIZATION, AND NONCARBOXYLASE ROLES OF BIOTIN, Janos Zempleni

REgUlation OF PHOSPHORUS HoMEOSTASIS BY THE TyPE IIa Na/PhOSPHATE COTRANSPORTER, Harriet $S$. Tenenhouse

SELENOPROTEIN P: AN EXTRACELlULAR PROTEIN WITH UNIQUE

Physical Characteristics AND a Role IN SELENIUM

HOMEOSTASIS, Raymond F. Burk and Kristina E. Hill

ENERGy InTAKE, MEAL FREQUENCY, AND HEALTH:

A Neurobiological PersPeCtive, Mark P. Mattson

REDOX REGULATION BY INTRINSIC SPECIES AND EXTRINSIC

NUTRIENTS IN NORMAL AND CANCER CELLS,

Archana Jaiswal McEligot, Sun Yang, and Frank L. Meyskens, Jr.

REgUlATION OF GENE TRANSCRIPTION By BOtANICALS: NOVEL

REGUlATORY MECHANISMS, Neil F. Shay and William J. Banz. 
Polyunsaturated FATTy ACID REGULATION OF GENES OF LIPID

METABOLISM, Harini Sampath and James M. Ntambi

SingLE NUCLEOTIDE POLYMORPHISMS THAT INFLUENCE LIPID

METABOLISM: INTERACTION WITH DIETARY FACTORS,

Dolores Corella and Jose M. Ordovas

THE INSULIN RESISTANCE SYNDROME: DEFINITION AND DIETARY

APPROACHES TO TREATMENT, Gerald M. Reaven

DeVelopmental Determinants of Blood Pressure in Adults, Linda Adair and Darren Dahly

PeDiatric Obesity and InSUlin RESISTANCE: Chronic Disease RISK AND IMPLICATIONS FOR TREATMENT AND PREVENTION BEyOND Body WeIGHT ModifiCATION, M.L. Cruz, G.Q. Shaibi, M.J. Weigensberg, D. Spruijt-Metz, G.D.C. Ball, and M.I. Goran

ANNUAL LIPID CYCLES IN HIBERNATORS: INTEGRATION OF

PHYSIOLOGY AND BEHAVIOR, John Dark

Drosophila Nutrigenomics CAN PROVIDE Clues to HuMaN GENE-NuTRIENT INTERACTIONS, Douglas M. Ruden, Maria De Luca, Mark D. Garfinkel, Kerry L. Bynum, and Xiangyi Lu

The Cow as a Model to Study Food InTAKe Regulation, Michael S. Allen, Barry J. Bradford, and Kevin J. Harvatine

The Role of Essential FatTy ACIDS IN DEVElopment, William C. Heird and Alexandre Lapillonne

INDEXES

Subject Index

Cumulative Index of Contributing Authors, Volumes 21-25

605

Cumulative Index of Chapter Titles, Volumes 21-25

608

ERRATA

An online log of corrections to Annual Review of Nutrition chapters may be found at http://nutr.annualreviews.org/ 